\title{
Study on the Relationship between the Economic Growth and Industrial Structure Changes
}

\author{
Ya-Nan Shen \\ Harbin university of Commerce \\ Harbin, China \\ E-mail:Shenyn315@163.com
}

\author{
Fang-Fang Zhang \\ Harbin university of Commerce \\ Harbin, China \\ E-mail:2933928451@qq.com
}

\begin{abstract}
This paper focus on the general least squares method to explore the research topic, combining the time series analysis method to carry on the comprehensive examination to the original variable data; we construct a gray correlational degree model to estimate the relationship between subjects. There is a cointegration relationship between the economic growth and industrial structure, the second industry has the greatest impact on the economic growth; the influence of the tertiary industry gradually increased. Using the quantitative analysis, we show that there is a positive correlation between the added value of three industries and the economic growth. The second industry has the highest contribution to economic growth, followed by the tertiary industry, and finally the first industry. The innovation of the paper lies in the use of time series and gray relational analysis.
\end{abstract}

Keywords-economic growth; industrial structure change; comprehensive test; gray correlation analysis; regression estimation

\section{INTRODUCTION}

In the process of modern economic growth, there is an inseparable relationship between economic growth and industrial structure changes. The industrial structure changes are resulted from economic growth, and affect the quality and level of economic development. The equilibrium level of industrial structure and economic structure reflect a country or a region's economic development direction and level, restricting economic development speed.[1]. However, Neoclassical economic growth theory didn't take into account the role of industrial structure changes in the economic growth, instead, from Hoffman's (1958) Industrialization Stage theory, Lewis's (1954) Dualistic Economic Structure theory, to the Chenery's (1989) Industrial Structure theory and Kuznets's Industrial Structure Evolution law, The Structuralism of development economics have made efforts to improve and develop the neoclassical economics[2].

Reforming and opening up for more than 30 years, China's rapid economic growth was known as the "Chinese style of development". Based on the neoclassical and new economic growth theory, domestic scholars have done a lot of theoretical and empirical research on "Chinese style of development". Guo Kesha (1993), Liu Wei (1995), Zhou Zhenhua(1995)and others focused on theoretical analysis[3-5]. With the further development of China's economy, the academia paid more attention on empirical research. According to national or provincial data, domestic scholars explored the relationship between economic growth and industrial structure changes. Zhai Cuixia (2013) used the data of Liaoning province from 1978 to 2011 to conduct statistical analysis, the results showed that there was a long-term equilibrium relationship between industrial structure and economic growth, and a one-way Grainger causal relationship between industrial structure adjustments and economic growth; economic growth promotes the adjustment of industrial structure, rather than structural adjustment promotes economic growth. Chen Yiwei (2012) reached a similar conclusion[6-7]. Huang Bingjie, Sun Xujie(2013),Yuan Xiao jun, Sun Jinshan(2013) adopted co-integration analysis for different provinces and autonomous regions, and the empirical results showed there was a long-term equilibrium relationship between industrial structures change and economic growth[8-9]. Studied the data from 1979 to 2011 of Beijing, Li Dongjun, Zhang Hui(2013) pointed out that there was no significant causal relationship [10]; Luo Shihua (2012) thought that there was no interaction between economic growth and industrial structure changes in Yunnan province [11]; By studying the relationship between China's economic growth and industrial structure adjustment under the background of the new normal economy ,Wang $\mathrm{Yu}$, Li Jian (2016) hold the opinion that the change of industrial structure was the Grainger reason of economic growth, but couldn't draw a conclusion that economic growth was the Grainger reason of industrial structure change [12].

Although there are a lot of research results, there are still some problems to be solved: first, the scholars got different conclusions based on different theoretical basis and disciplinary perspective, so the empirical results are not consistent, which makes it difficult to be convinced. Second, in the absence of corresponding measurement test, some of the literature construct regression analysis on the time series data directly, which may easily resulted in a false regression, so the conclusions need to be further tested. Third, even though the empirical results were obtained, but it's only a quantitative correlation, a description from the overall data of China or a region, which can't fully explain the periodic characteristics of China's industrial structure changes.

Therefore, based on the data of the primary, the secondary, the tertiary industry and GDP from 1978 to 2015 in China which having examined by metrological analysis, this paper will apply the method of Grainger causality test to figure out the relationship among the variables and the grey correlation 
degree analysis to calculate the share of GDP attributed to each of the three sectors in stages.

\section{THE SUMMARY OF BASIC THEORY}

The method of grey correlation degree analysis was proposed by Julong Deng in 1982, which has been widely used in various fields of our country. The gray relational analysis is based on the gray system theory; the basic idea is to analyze the tightness degrees between the systems and the elements by means of the gray relational analysis model. The greater the value of the association degree, the more closely the relationship between the reference sequence and the comparison sequence, the development direction of the variable system in the comparative sequence is similar to that of the reference sequence. The higher the degree of fit, the closer the relationship with the reference sequence is [13].

The operations of the grey correlation degree analysis method are to select the reference sequence and the comparison sequence of the research variables firstly, and to initialize the original variable sequence. Generally we use the dimensionless processing to get the matrix $X_{i}^{\prime}=X_{i}(1)=\left(\left(X_{i}^{\prime}(1), X_{i}^{\prime}(2) X_{i}^{\prime}(n)\right)\right),(\mathrm{i}=0,1,2, \ldots \mathrm{m})$; Use the matrix to find the difference sequence, denoted by $\Delta_{\mathrm{i}}(\mathrm{k})=$ $\left|\mathrm{x}_{0}^{\prime}(\mathrm{k})-\mathrm{x}_{\mathrm{i}}^{\prime}(\mathrm{k})\right| \quad, \quad \Delta_{\mathrm{i}}=\left(\Delta_{\mathrm{i}}(1), \Delta_{\mathrm{i}}(2), \ldots, \Delta_{\mathrm{i}}(\mathrm{n})\right) \quad, \quad(\mathrm{i}=$ $1,2, \ldots, \mathrm{m})$;Find out $\Delta_{\mathrm{i}}$ 's maximum and minimum difference,denoted by: $\mathrm{M}=\max _{\mathrm{i}} \max _{\mathrm{k}} \Delta_{\mathrm{i}}(\mathrm{k}), \mathrm{m}=\min _{\mathrm{i}} \min _{\mathrm{k}} \Delta_{\mathrm{i}}(\mathrm{k})$. Figure out the correlation coefficient $\gamma_{0 i}(k)$ which describing the correlation degrees between the reference sequence and the comparison sequence at the $\mathrm{K}$ moment, denoted by: $\gamma_{0 i}(k)=\frac{m+\rho M}{\Delta_{i}(k)+\rho M}, \rho \in(0,1), \mathrm{k}=1,2,3, \ldots, \mathrm{n} ; \mathrm{i}=1,2,3, \ldots, \mathrm{m}$. Among them, $\rho$ represents the resolution coefficient, which is used as improving the significance of difference between the correlation coefficient. The smaller the $\rho$, higher the difference between the correlation coefficient. Generally, it values between $(0,1)$, this paper selects $\rho=0.5$.

Due to the large number of correlation coefficients matrix, the amount of information is relatively large but scattered, which may not perfectly reflect the degree of correlation between series; there, the ref-average value index is used to reflect the concentration trend of the correlation coefficients information. According to the calculated degree of relevance, sort and analyze the results, the bigger the $\gamma_{0 \mathrm{i}}$, the closer the comparison between the series and the reference sequence is; and vice versa[14].

\section{AN EMPIRICAL ANALYSIS OF ECONOMIC GROWTH AND INDUSTRIAL STRUCTURE CHANGE IN CHINA}

\section{A. The construction of econometric model}

In this part of the model construction, draw lessons from the classic Cobb-Douglas production function model(C-D production function model):

$$
\mathrm{Y}=A \mathrm{~L}^{\alpha} \mathrm{K}^{\beta} \mathrm{e}^{\mu}
$$

Where $\mathrm{Y}$ is the total output, $\mathrm{K}$ is the capital turnover, $\mathrm{L}$ is the amount of labor, and A for the efficiency coefficient.
For the classical model, in on both sides of the exponential model, there is:

$$
\operatorname{LnY}=\operatorname{Ln} A+\alpha \operatorname{LnL}+\beta \operatorname{LnK}+\mu
$$

Make: $\mathrm{X}^{*}=\mathrm{LnA},=\mathrm{LnY}, \mathrm{L}^{*}=\mathrm{LnL}, \mathrm{K}^{*}=\mathrm{LnK}$, it can be turned into linear regression equation

$$
\mathrm{Y}^{*}=\mathrm{X}^{*}+\mathrm{L}^{*}+\mathrm{K}^{*}+\mu
$$

Differentiating the logarithmic function on the two sides, there are:

$$
\frac{d Y}{Y}=\alpha \frac{d L}{L}+\beta \frac{d K}{K}
$$

Get: $\alpha=\frac{\frac{d Y}{\mathrm{Y}}}{\frac{\mathrm{dL}}{\mathrm{L}}}, \beta=\frac{\frac{\mathrm{d} \mathrm{Y}}{\mathrm{Y}}}{\frac{\mathrm{dK}}{\mathrm{K}}}$. Among them, the partial slope coefficient $\frac{\frac{d Y}{\mathrm{Y}}}{\frac{\mathrm{L}}{\mathrm{L}}}(\alpha)$ represents the elasticity of the total output of the labor factor $(L), \frac{\frac{d Y}{Y}}{\frac{d K}{K}}(\beta)$ represents the elasticity of the output of the capital element $(\mathrm{K})$.

The formula (1) is transformed by the formula (3) to obtain the formula (4):

$$
\log (\mathrm{GDP})=\beta_{0}+\beta_{1} \log \left(\mathrm{x}_{1}\right)+\beta_{2} \log \left(\mathrm{x}_{2}\right)+\beta_{3} \log \left(\mathrm{x}_{3}\right)+\varepsilon
$$

The formula (4) is the empirical model established by the article, which is used to analyze the contribution of the three industrial changes to economic growth in China.

The dependent variable used in this paper is $\mathrm{Y}$, ie, gross domestic product (GDP), and the independent variables are $\mathrm{X} 1$, $\mathrm{X} 2, \mathrm{X} 3$, ie, the added value of the first, second and third industries. In order to improve the accuracy of the analysis, the data logarithmic processing does not change the original cointegration relationship of the fine features of the original variable logarithmic processing, and we get the data used in the article from the National Bureau of Statistics database site.

The time period of this paper is from 1978 to 2015, and the data are calculated according to the constant price of the year. This paper doesn't remove the factor (price changes) which can be regarded as the common factor of the variable and does not affect the analysis results.

\section{B. Comprehensive test}

As a general rule, nonstationary time series variables should not be used in regression models, in order to avoid the problem of spurious regression. So, before the empirical analysis, firstly we are going on the stationary test to the raw data, the test results are as follows: 
TABLE I. CONSISTENCY TEST OF RAW DATA

\begin{tabular}{|c|c|c|c|}
\hline Series & ADF-value & $\begin{array}{c}\mathbf{5 \%} \text { confidence } \\
\text { level }\end{array}$ & P-value \\
\hline LGDP & -1.5289 & -2.95402 & 0.5068 \\
\hline LX1 & -0.98966 & -2.94584 & 0.7466 \\
\hline LX2 & -1.4623 & -2.95402 & 0.5398 \\
\hline LX3 & -2.3592 & -2.95402 & 0.1606 \\
\hline
\end{tabular}

According to the results of the stability test of the original data, the ADF test value of the variable LGDP is -1.5289 , greater than $5 \%$ of the significance level of -2.95402 ; the probability of accepting the null hypothesis is 0.5098 , so the original variable LGDP series is not stable .The ADF-value of the variable LX1 is -0.98966, we can't reject the null hypothesis. Our results we obtained show that LX1 is non stationary. Similarly, the LX2 and LX3 series are not stable.

TABLE II. STATIONARITY TEST OF FIRST ORDER DIFFERENTIAL SERIES

\begin{tabular}{|c|c|c|c|}
\hline Series & ADF value & $\begin{array}{c}\mathbf{5 \%} \text { confidence } \\
\text { level }\end{array}$ & P value \\
\hline $\mathrm{D}(\mathrm{LGDP})$ & -3.66787 & -2.95402 & 0.0095 \\
\hline $\mathrm{D}(\mathrm{LX} 1)$ & -3.98715 & -2.94584 & 0.0039 \\
\hline $\mathrm{D}(\mathrm{LX} 2)$ & -2.41241 & -2.94584 & 0.1455 \\
\hline $\mathrm{D}(\mathrm{LX} 3)$ & -3.82323 & -2.94584 & 0.006 \\
\hline $\mathrm{D}(\mathrm{LX} 2,2)$ & -5.38709 & -2.9484 & 0.0001 \\
\hline
\end{tabular}

The first order difference of the original variable sequence D (LGDP) has an ADF test value of -3.66787, a significance test of less than $5 \%$ of the critical value of -2.95402 , the probability of accepting the original hypothesis is 0.0095 , so the first order difference variable D (LX1) and D (LX3) sequences are stable. The first order difference variables $\mathrm{D}$ (LX1) and D (LX3) are smooth. The first order differential variable D (LX2) has an ADF test value of -2.41241 , a significant test value of more than $5 \%$ is -2.94584 , and a probability of acceptance of the original hypothesis is 0.1455 , so a first order differential sequence is not smooth.

It can be seen that the original series LGDP, LX1, LX3 are the same order integration.

At present, there are many technical processing models to test and estimate the series of cointegration relations, the general method is to use OLS (Ordinary lest squares) for regression estimation, and then to carry out the stability test of the residual value. We will use the ADF value to determine whether there is a cointegration relationship among the variables.

After the regression of the time series, the long-term equilibrium equation of China's economic growth and industrial structure is:

$$
\mathrm{LGDP}=1.5892+0.237475 * \mathrm{LX} 1+0.7249 * \mathrm{LX} 3
$$

The residual sequence of the regression equation was: ADF statistic of -8.787133 , P value of 0.0000 , much less than $5 \%$ of the significant level. Therefore, we can reject the null hypothesis that there is a cointegration relationship between the variables LGDP, LX1 and LX3, that is, there is a long-term equilibrium relationship between GDP growth and industrial structure between 1978 and 2015.

The Granger test is used to test the Granger causality between economic growth (LGDP) and industrial structure (LX1, LX2, LX3). The results are shown in the following table:

\section{TABLE III. VARIABLES GRANGER CAUSALITY ANALYSIS}

\begin{tabular}{|c|c|c|}
\hline Null Hypothesis: & F-Statistic & Prob. \\
\hline LX1 does not Granger Cause LGDP & 1.2716 & 0.2946 \\
\hline LGDP does not Granger Cause LX1 & 9.74961 & 0.0005 \\
\hline LX3 does not Granger Cause LGDP & 3.2769 & 0.0118 \\
\hline LGDP does not Granger Cause LX3 & 0.7705 & 0.4714 \\
\hline LX3 does not Granger Cause LX1 & 5.63951 & 0.0082 \\
\hline LX1 does not Granger Cause LX3 & 0.05667 & 0.945 \\
\hline
\end{tabular}

For the null hypothesis "LX1 is not the LGDP Granger cause", the test under the F statistic value of 1.2716, P-value of 0.2946, could not reject the original hypothesis; for the original hypothesis "LGDP is not LX1 Granger reasons", under test F statistic value of 9.74961, p value of 0.0005 , rejected the null hypothesis. So that economic growth is the reason of the first industry changes of Granger; but we could not think that the first industrial change is the economic growth of Granger reasons.

For the null hypothesis "LX3 is not the LGDP Granger cause", the test under the F statistic value of 3.2769 , P value of 0.0118 , rejected the original hypothesis; for the original hypothesis "LX3 is not LGDP Granger reasons", under test F statistic value of $0.7705, \mathrm{P}$ value of 0.4714 , rejected the original hypothesis. Therefore, the third industry changes are the reasons of the economic growth of Granger, but can't draw the economic growth is the third industry changes in the Granger reasons.

For the null hypothesis "LX3 is not the cause of the LX1 Granger", the test under the F statistic value of 5.63951, P value of 0.0082 , rejected the original hypothesis; for the original hypothesis "LX3 is not LGDP Granger reasons", under test F statistic value of 0.05667 , P value of 0.945 , could not reject the original hypothesis. Therefore, there is a certain correlation between the first and the third industry. The change of the tertiary industry is the Granger reason of the change of the primary industry, but the change of the primary industry is not the reason of the change of the tertiary industry.

The results suggest that economic growth is the reason for the change of the first industrial structure, and the change of the tertiary industry promotes economic growth and promotes the change of the primary industry structure, which shows that the tertiary industry has obvious effect in economic growth.

\section{Gray correlation analysis}

In the previous analysis, the influence of the secondary industry on China's economic growth was eliminated, and the gray correlation analysis was used to analyze the concrete manifestation of the three industrial changes in China's economic growth. According to the characteristics of China's industrial structure changes, the relationship between the three 
industries and economic growth is calculated in stages, and the results are analyzed as followed:

TABLE IV. THE RELATIONSHIP BETWEEN ECONOMIC GROWTH AND THE INDUSTRIAL STRUCTURE OF THE PHASE CALCULATION (1)

\begin{tabular}{|c|c|c|c|}
\hline Period & $\begin{array}{c}\text { Primary } \\
\text { Industry }\end{array}$ & $\begin{array}{l}\text { Secondary } \\
\text { Industry }\end{array}$ & $\begin{array}{l}\text { Tertiary } \\
\text { Industry }\end{array}$ \\
\hline $1978-1984$ & 0.520252 & 0.735842 & 0.648027 \\
\hline $1985-2002$ & 0.711136 & 0.912479 & 0.766124 \\
\hline $2003-2010$ & 0.623401 & 0.904896 & 0.881102 \\
\hline $2011-2015$ & 0.798839 & 0.653323 & 0.631217 \\
\hline $1978-2015$ & 0.745932 & 0.977438 & 0.820361 \\
\hline
\end{tabular}

TABLE V. THE RELATIONSHIP BETWEEN ECONOMIC GROWTH AND THE INDUSTRIAL STRUCTURE OF THE PHASE CALCULATION (2)

\begin{tabular}{|c|c|c|c|}
\hline Period & $\begin{array}{c}\text { Primary } \\
\text { Industry }\end{array}$ & $\begin{array}{c}\text { Secondary } \\
\text { Industry }\end{array}$ & $\begin{array}{c}\text { Tertiary } \\
\text { Industry }\end{array}$ \\
\hline $1978-1984$ & 0.422302 & 0.653817 & 0.540112 \\
\hline $1985-2002$ & 0.632521 & 0.867392 & 0.691268 \\
\hline $2003-2010$ & 0.529473 & 0.854459 & 0.826021 \\
\hline $2011-2015$ & 0.730849 & 0.561395 & 0.540443 \\
\hline $1978-2015$ & 0.693277 & 0.964824 & 0.763952 \\
\hline
\end{tabular}

Using different resolution coefficient $\rho$ value to calculate, the results obtained the same.

To investigate the changes in the industrial structure of China in a phased manner and the degree of contribution of various industries to China's economic growth is also changing.

In the first stage (1978-1984), the degree of correlation between China's tertiary industry and GDP is ranked by $\gamma_{02}>$ $\gamma_{03}>\gamma_{01}$, that is, the secondary industry $>$ tertiary industry $>$ primary industry. During this period, the first industry contributed the least to the economic growth, while the secondary industry showed a strong momentum of development; the tertiary industry growth was slightly lower than the secondary industry.

The second stage (1985-2000), the impact of the secondary industry on economic growth has increased significantly, exceeding the impact of the other two industries.

The third stage (2003 - 2010), the dominant position of the secondary industry remains unchanged, but the tertiary industry on the impact of economic growth is as much as that of the secondary industry. On the contrary, the relevance of the first industry to economic growth has increased, compared with the first stage, and has a significant reduction of the degree compared with the previous phase.

The third stage(2011 - present), the correlation between the primary industry and economic growth is much higher than that of the secondary and tertiary industries, the value of the secondary and tertiary is lower than the previous stage; the author believes that this phenomenon is due to the lack of data. Using the mean value to analyze, it is not easy to reflect the discretization of information.

From the overall situation of China, the impact of the secondary industry on China's economic growth is the largest, far more than the primary and tertiary industry, which is in line with the objective law of China's economic development.

\section{Regression estimation}

Since the DW statistical value of the original sequence regression equation is about 0.209 , it shows that there is a high degree of sequence correlation among the sequences, which does not satisfy the statistical significance. The first order difference of the observed sequence is used to eliminate the influence of sequence correlation and improve the accuracy of the model. Regression analysis of the sequence after the first order difference is repeated, the result is as follows:

$$
\begin{gathered}
\Delta \mathrm{LGDP}=0.013187+0.204454 * \Delta \mathrm{LX} 1+0.479707 \\
* \Delta \mathrm{LX} 2+0.247523 * \Delta \mathrm{LX} 3 \\
(6.346717) \quad(15.17360) \\
(26.20539) \quad(13.99518) \\
R^{2}=0.9945 \quad \overline{\mathrm{R}}^{2}=0.9940 \quad \mathrm{~F}=1993.006 \\
\mathrm{DW}=1.6920 \quad \mathrm{P}=0.00000
\end{gathered}
$$

The results we obtained demonstrate that the $\mathrm{T}$-value of each variable is significant by the correction of the original sequence equation, which shows that the linear effect of the first and the third industry on GDP is very significant, and the fitting degree of the model is better. At the same time, the DW statistic is 1.6920, and the series does not have obvious autocorrelation. The determinants $\mathrm{R}^{2}$ and $\overline{\mathrm{R}} 2$ are both 0.99 , indicating that $99 \%$ of the effects of economic growth and industrial structure change can be explained by the equation. Only $1 \%$ can't be explained. The sample returns to the point of the sample high degree of fit.

From the results of the regression equation, it can be seen that the average output value of the first industry increases by $0.2044 \%$ for every $1 \%$ of the output value of the first industry. The average output value of the secondary industry increases by $0.4797 \%$ for the second industry. The output value of the tertiary industry increases by $1 \%$ an average increase of $0.2475 \%$.

Compared with the contribution rate of each industry to economic growth, our results present that there is a positive correlation between the first, second and tertiary industries and economic growth in China's economic growth process, which is in line with the influences of the three industries on GDP . The second industry has the greatest contribution to economic growth, followed by the tertiary industry, and finally the first industry, which is consistent with the status of China's industrial structures. 


\section{CONCLUSION AND SUGGESTION}

\section{A. Conclusion}

According to the classical economics, this research explores the relationship between economic growth and industrial structure change in China, and makes a quantitative analysis using econometrics to establish the relationship model between China's economic growth and the first, second and third industries. This study yields the following results:

Firstly, using ADF test to verify the smoothness of time series data, the variables LGDP, LX1, LX2, LX3 are not stable, the first-order difference under the conditions of the variable in addition to LX2 are stable, we can see the original sequence LGDP, LX1, LX3 is the same order of the whole, there is a co-integration between the variables. Secondly, using the two-step co-integration test of Engle Granger, we can safely draw the conclusion that there is a co-integration relationship between China's economic growth and industrial structure (LX1, LX3).Thirdly,. It shows that the tertiary industry has a catalytic role in economic growth, and through economic growth in turn leads to the adjustment of the first industrial structure. Fourthly, according to the estimation results of ordinary least squares regression, there is a positive correlation between the added value of the primary, secondary, tertiary industries and the economic growth. Among them, the secondary industry has the strongest correlation with economic growth. Compared with the added value of the secondary industry, the correlation between the added value of the tertiary industry and the economic growth is slightly higher and there is a certain gap. Quantitative calculation of the first, second, tertiary industry and economic growth, the estimated coefficient are $0.2044,0.4797,0.2475$, which means that China's primary, second and tertiary industries increased by $1 \%$ for each additional value, economic growth increased by $0.2044 \%$, $0.4797 \%, 0.2475 \%$. Fifth, through the phase calculation of the relationship between China's three industries and economic growth, the secondary industry has the greatest effect on economic growth, followed by the tertiary industry.

The innovation of this paper lies in the applications of the time series analysis and gray relational degree method to research the theme, the shortcoming of this paper is that there is no research on the internal associations of the three industries, which requires for further research.

\section{B. Policy suggestions}

On the basis of above research results, the author puts forward the proposals of healthy and rational development of China's economy under the condition of new normal economy.

1) Under the background of global economic diversification, take the industrial structure to optimize the road to economic growth. Comprehensive use of combat, protection, supervision, prevention functions, active services to protect the supply side of the structural reform and to protect the healthy development of the real economy. Firmly promote the supply-side structural reform and improve the total factor productivity. The supply-side structural reform focuses on the liberation and development of social productive forces, with the reform of the way to promote the structural adjustment, reduce inefficiencies and low-end supply, expand effective and high-end supply, and increase supply agencies to adapt to changes in demand and flexibility, improve total factor productivity.

2) The impact of the secondary industry on China's economic growth is the largest, but China's secondary industry is not refined, should promote the industrial development to Technology-rich and high labor productivity of the industry. At present, China's secondary industry in the proportion of GDP has been high, but China's industrial type concentrated in the labor-intensive industries, industrial development presents a low technological content, the rate of return on investment is not satisfactory. The government needs to take corresponding policies to increase the promotion of scientific and technological innovation. In the process of promoting the adjustment of industrial structure to the high-tech development, we should increase the implementation of innovation-driven strategy, improve the capability of independent innovation, expand the space for the introduction of technology, and handle the unemployment and related problems caused in the short term.

3) The impact of the tertiary industry on China's economic growth has been continuously improved. It is necessary to vigorously develop the tertiary industry by accelerating the adjustment, optimization and upgrading of China's industrial structure at the present stage. Requiring the government in the development of economic policies need to give full consideration to the importance of the tertiary industry, to put the development of the tertiary industry (mainly referring to the service industry) in a core position, to standardize the principles of the industry access, to enhance the overall level of the tertiary industry; narrow the gap with developed countries and promote the healthy development of the national economy.

4) In the context of the new economy, China's economic slowdown is to make better progress. Leading the economic development of the new normal is to take the initiative. Pay more attention to the development of quality and efficiency, from the past mainly to see how fast the growth rate of change to see how good quality and efficiency. We must correctly handle the current relationship between economic growth and industrial structure changes, to achieve a low level of supply and demand balance to a high level of supply and demand balance.

\section{ACKNOWLEDGMENT}

This research was financially supported by the Philosophy and Social Science project of Heilongjiang Province (No: 16TJC01); the College students innovation and entrepreneurship project of Heilongjiang Province (No: 201610240026)

\section{REFERENCES}

[1] Yue Li, Ping Li. Industrial Economics [M]. Dalian: Northeastern University of Finance \& Economics Press, 2002.76

[2] Feng Chen .Study on the Empirical Study on the Relationship between Economic Growth and Industrial Structure Change [J] .New West, 2013,15

[3] Kesha Guo. Transformation of Industrial Structure and Economic Growth Model [J]. Economic Science .1993,1 
[4] Cuixia Zhai. An Empirical Study on the Relationship between Industrial Structure and Economic Growth - Based on the 30-year Change of Liaoning Industrial Structure [J] .Journal of Social Sciences, 2013,2

[5] Bingjie Huang, Xujie Sun. Discussion on Dynamic Relationship between Industrial Structure and Economic Growth - An Empirical Study of Shandong Province Based on VAR Model. Technical Economics and Management Research, 2013,5

[6] Dongjun Li, Hui Zhang. Study on the relationship between industrial structure and economic growth in Beijing and its causes [J]. Journal of Northeastern University (Social Science Edition), 2013,2

[7] Shihua Luo. Study on the Relationship between Industrial Structure Change and Economic Growth in Yunnan Province [J]. Journal of Yunnan University of Finance and Economics (Social Science Edition), 2012,5

[8] Yu Wang, Jian Li. Study on the Relationship between Economic Growth and Industrial Structure under the New Normal Situation [J]. Industrial Technology \& Economy, 2016,2

[9] Xiao-li Liu, Ding-xiang Liu. An Gray Correlation Analysis of Chongqing's Economic Growth and Industrial Structure [J]. Statistics \& Decision, 2010,13

[10] Liu Sifeng. Gray system theory and its application [M]. Beijing: Science Press, 2000

[11] Xiaocong Zhang. The basis of econometrics [M]. Tianjin: Nankai University Press, 2004 